Supporting Information for:

\title{
The Mechanism of Epoxide Carbonylation by [Lewis Acid $]^{+}\left[\mathrm{Co}(\mathrm{CO})_{4}\right]^{-}$Catalysts
}

Tamara L. Church, Yutan D. Y. L. Getzler, and Geoffrey W. Coates*

Department of Chemistry and Chemical Biology

Baker Laboratory, Cornell University, Ithaca, New York 14853-1301

\section{Calibration Curve for $\beta$-Valerolactone ( $\beta$-VL) in 1,2-Dimethoxyethane (DME)}

$\beta$-VL was pipetted into a tared $10-\mathrm{ml}$ volumetric flask. The mass of added lactone was recorded, and the flask filled to $10 \mathrm{ml}$ with DME. After the lactone was dissolved, the resulting solution was drawn into a syringe. The syringe was placed in the injection port of a 100-ml stainless steel Parr reactor, modified for use with a MettlerToledo ReactIR 4000 Reaction Analysis System fitted with a Sentinel DiComp High Pressure Probe. After five minutes, a background spectrum of the reactor was recorded, and the solution was then injected into the reactor and stirred for several minutes. An IR spectrum of the solution was recorded, and the $\beta$-VL absorbance was measured as the height of the peak at $1827.3 \mathrm{~cm}^{-1}$ to a two-point baseline (defined at $1865.9 \mathrm{~cm}^{-1}$ and $\left.1772.7 \mathrm{~cm}^{-1}\right)$. This procedure was performed for a total of 31 independently prepared samples, including one where $\beta$-VL was added. The measured values of absorbance were plotted against $[\beta-\mathrm{VL}]$ (Figure S1) and the data fit to polynomials of increasing order until the variance $\left(\sigma^{2}\right)$ was minimized, at order $=2$. 


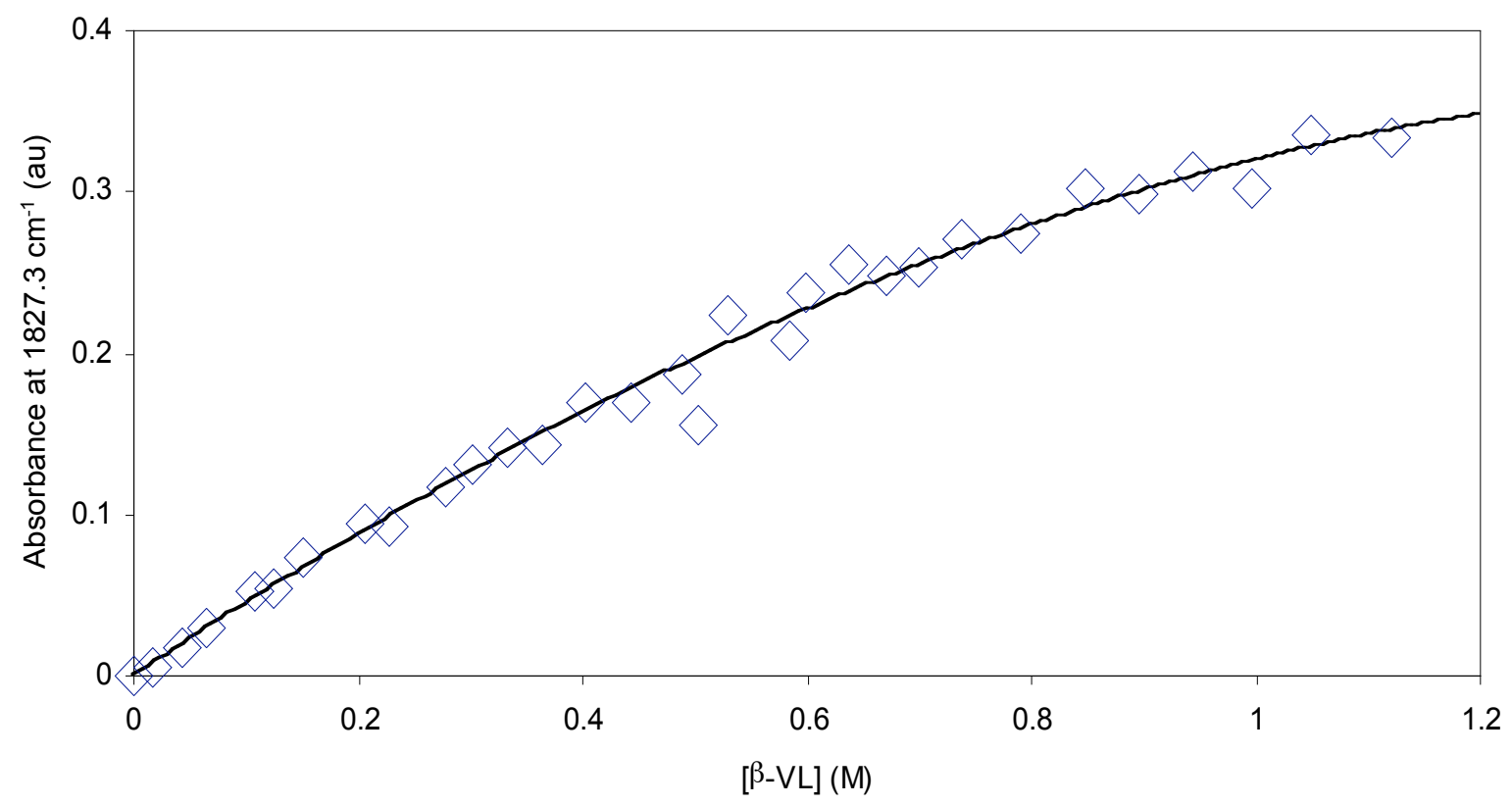

Figure S1. Absorbance at $1827.3 \mathrm{~cm}^{-1}$ as a function of $[\beta-V L]$. Black curve is the function $A s_{1827.3}=-0.000871+0.467$ $[\beta-\mathrm{VL}]-0.147[\beta-\mathrm{VL}]^{2}$.

\section{Effect of Carbon Monoxide Pressure on $\operatorname{Abs}_{\beta-V L}$}

A sample of $\beta$-VL in DME was prepared, and the IR spectrum recorded as described above. Carbon monoxide (60 psi) was added to the reactor, and the solution stirred for several minutes. An IR spectrum was recorded, and the absorbance measured as before. This procedure was repeated as more $\mathrm{CO}$ was added in increments of $\sim 50$ psi. The pressure of carbon monoxide did not have a significant effect on the absorbance of $\beta$-VL at the frequency observed $\left(1827.3 \mathrm{~cm}^{-1}\right)$.

\section{Effect of Carbon Monoxide Pressure on the Rate of Carbonylation of Epoxides by $\left[(\mathrm{salph}) \mathrm{Al}(\mathrm{THF})_{2}\right]^{+}\left[\mathrm{Co}(\mathrm{CO})_{4}\right]^{-}, 1$}

Four carbonylations with were performed with $[\mathrm{EB}]_{0}=1.24 \pm 0.01 \mathrm{M}, P_{\mathrm{CO}}=300$ $\pm 10 \mathrm{psi},[\mathbf{1}]=11.6 \pm 0.1 \mathrm{mM}$, and $\mathrm{T}=25^{\circ} \mathrm{C}$. From these, the rate of carbonylation was calculated to be $(6.2 \pm 0.5) \mathrm{mM} / \mathrm{min}$. The reaction was then repeated using a range of $\mathrm{CO}$ 
pressures, from 220 to $1045 \mathrm{psi}$ (Table S1). In each case, the reaction rate was found to be within error of the rate determined for $P_{\mathrm{CO}}=300 \mathrm{psi}$.

\begin{tabular}{|c|c|c|}
\hline Entry & $\begin{array}{l}P_{\mathrm{CO}} \\
\text { (psi) }\end{array}$ & $\begin{array}{c}\text { Rate of } \beta-V L \text { Formation } \\
(\mathrm{mM} / \mathrm{min})\end{array}$ \\
\hline 1 & 220 & 5.9 \\
\hline 2 & 300 & $6.2 \pm 0.5^{b}$ \\
\hline 3 & 400 & 6.3 \\
\hline 4 & 530 & 6.0 \\
\hline 5 & 625 & 6.7 \\
\hline 6 & 710 & 6.1 \\
\hline 7 & 815 & 6.0 \\
\hline 8 & 1045 & 6.5 \\
\hline
\end{tabular}

\section{Reaction of [(salph)AlOCH(Et) $\left.\mathrm{CH}_{2} \mathrm{Cl}\right]$ (4) with 4-F-C ${ }_{6} \mathrm{H}_{4} \mathrm{NCO}$ in THF- $d_{8}$}

In a glove box, [(salph)AlOCH(Et) $\left.\mathrm{CH}_{2} \mathrm{Cl}\right](5.46 \mathrm{mg}, 0.00811 \mathrm{mmol})$ was dissolved in THF- $d_{8}(0.70 \mathrm{ml}, 8.6 \mathrm{mmol})$, and $0.60 \mathrm{ml}$ of the solution was transferred into a pre-dried NMR tube modified with a Kontes valve. The NMR tube was then charged with 4-F- $\mathrm{C}_{6} \mathrm{H}_{4} \mathrm{NCO}(46 \mu \mathrm{l}, 0.40 \mathrm{mmol})$ via syringe, and the tube sealed. The sample was immediately transported to the INOVA $400 \mathrm{MHz}$ NMR spectrometer (equilibrated at 25 ${ }^{\circ} \mathrm{C}$ ) and spectra were recorded every $2 \mathrm{~min}$. The integral, I, of the imine resonance of the starting material $(\delta=9.22 \mathrm{ppm})$ was used to monitor the progress of the reaction. The initial rate was evaluated over the period $t_{0} \rightarrow t$ such that $I_{t}=0.95 I_{0}$ (Figure $S 2$ ). The slope and intercept of this graph were used to approximate the amount of OD that would be formed when during the 1-catalyzed carbonylation of EB in the presence of 4-F$\mathrm{C}_{6} \mathrm{H}_{4} \mathrm{NCO}$, in THF solution, vide infra. 


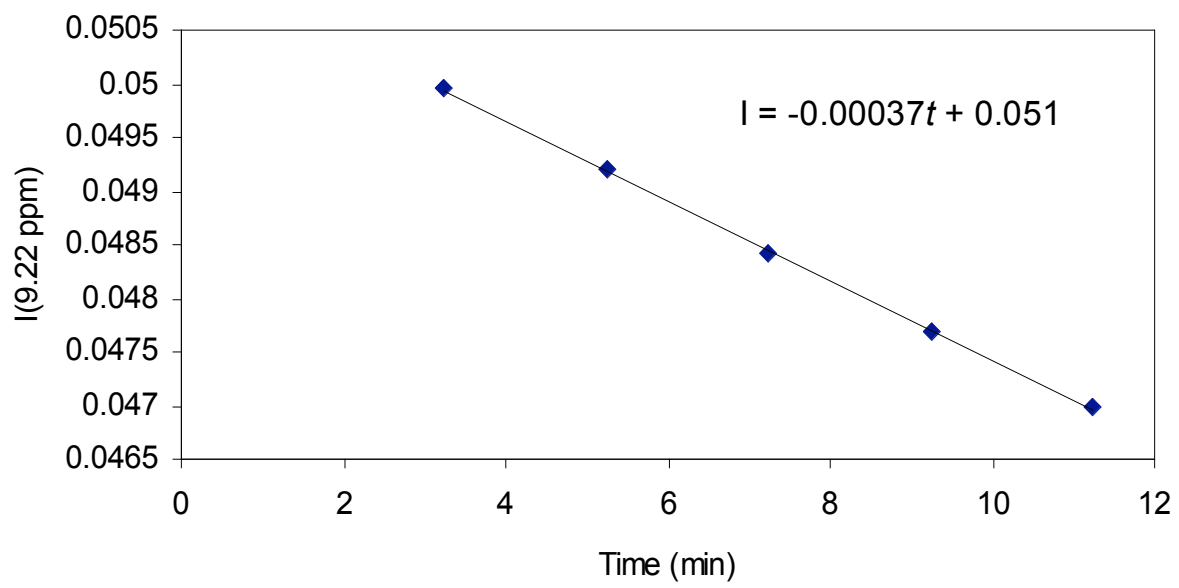

Figure S2. Integral, I, of the ${ }^{1} \mathrm{H}$ NMR resonance of [rac-(salph)AIOCH(Et) $\left.\mathrm{CH}_{2} \mathrm{Cl}\right]$ (4) at $9.22 \mathrm{ppm}$, in THF- $d_{8}$ solution and in the presence of $4-\mathrm{F}-\mathrm{C}_{6} \mathrm{H}_{4} \mathrm{NCO}$, as a function of time. Data shown, and slope calculated, for the period $t_{0} \rightarrow t$, where $I_{t}=0.95 I_{0}$.

Estimation of Product Ratio from the 1-Catalyzed Carbonylation of EB in THF, in the Presence of 4-F- $\mathrm{C}_{6} \mathrm{H}_{4} \mathrm{NCO}$

1) Initial Rate for the reaction of 4 with $4-\mathrm{F}-\mathrm{C}_{6} \mathrm{H}_{4} \mathrm{NCO}$ in THF- $d_{8}$

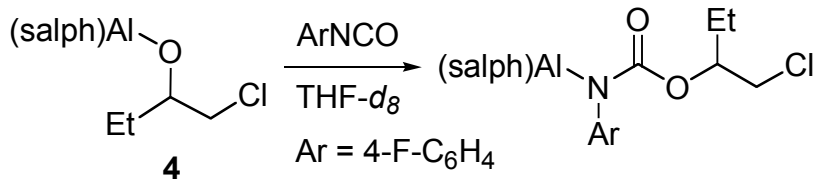

$$
[4]_{0}=0.0116 \mathrm{M},\left[4-\mathrm{F}-\mathrm{C}_{6} \mathrm{H}_{4} \mathrm{NCO}\right]_{0}=0.67 \mathrm{M}
$$

initial slope $=\frac{\mathrm{d}\left[\mathrm{I}_{4}\right]}{\mathrm{dt}}$ for $\left[4-\mathrm{F}-\mathrm{C}_{6} \mathrm{H}_{4} \mathrm{NCO}\right]=0.67 \mathrm{M}$

$$
=-0.000370 \mathrm{I} \cdot \mathrm{min}^{-1}
$$

intercept $=0.0511 \mathrm{I}$

$$
\text { so } \begin{aligned}
{\left[\frac{\mathrm{d}[4]}{\mathrm{dt}}\right]_{\text {init }} } & =\left(-0.000370 \mathrm{I} \cdot \mathrm{min}^{-1}\right)(0.0116 \mathrm{M} / 0.0511 \mathrm{I}) \\
& =-4.29 \times 10^{-6} \mathrm{M} \cdot \mathrm{min}^{-1}
\end{aligned}
$$

\section{2) Rate of carbonylation of EB by 1, in THF solution}

In THF, EB carbonylation by $\mathbf{1}$ is zero-order in EB. A solution of $\mathbf{1}(0.0116 \mathrm{M})$ in THF carbonylates EB (1.24 M) completely to $\beta-\mathrm{VL}$ in $90 \mathrm{~min}$.

$$
\text { so } \begin{aligned}
\frac{\mathrm{d}[ß-\mathrm{VL}]}{\mathrm{dt}} & =(1.24 \mathrm{M}) /(90 \mathrm{~min}) \\
& =1.4 \times 10^{-2} \mathrm{M} \cdot \mathrm{min}^{-1}
\end{aligned}
$$




\section{3) Comparison of rate of lactone formation with rate of reaction with isocyanate}

Assumptions:

i) Complex $\mathbf{4}$ is a suitable model for the aluminum-alkoxide teminus of $\mathbf{3 a}$, and both can be approximated as AlOR.

ii) During the carbonylation of epoxybutane (EB), as long as epoxide and CO are present, [3a] $=[\mathbf{1}]_{0}$ (i.e. the catalyst exists as AlOR).

iii) The rate of $\mathrm{B}-\mathrm{VL}$ formation from 3a is unaffected by the presence of $4-\mathrm{F}-\mathrm{C}_{6} \mathrm{H}_{4} \mathrm{NCO}$.

iv) The rate of insertion of 4-F- $\mathrm{C}_{6} \mathrm{H}_{4} \mathrm{NCO}$ into AlOR is unaffected by the presence of $\mathrm{CO}$.

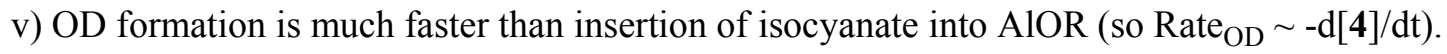

vi) Since isocyanate insertion is slow and very little reacts with $1,\left[4-\mathrm{F}-\mathrm{C}_{6} \mathrm{H}_{4} \mathrm{NCO}\right]_{\mathrm{t}}=[4-\mathrm{F}-$ $\left.\mathrm{C}_{6} \mathrm{H}_{4} \mathrm{NCO}\right]_{0}$ at all times.

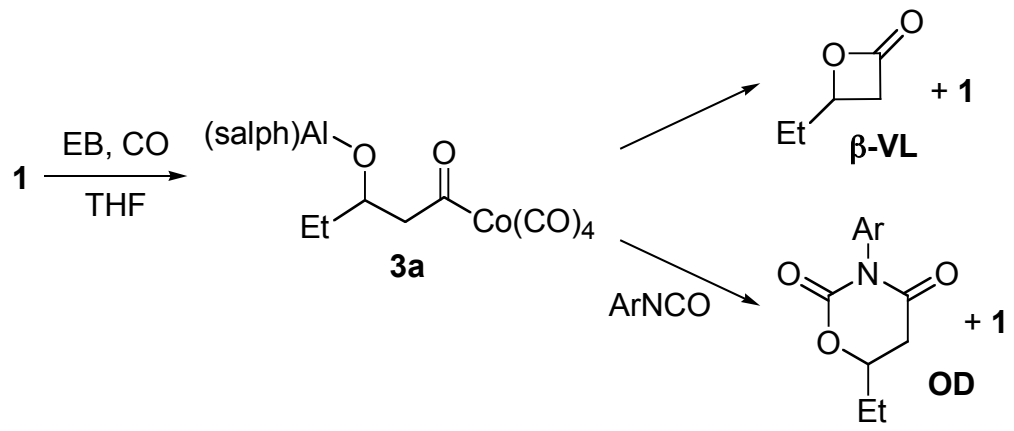

Then, for a carbonylation of EB run using $[1]=0.0116 \mathrm{M}$ and $\left[4-\mathrm{F}-\mathrm{C}_{6} \mathrm{H}_{4} \mathrm{NCO}\right]=0.67 \mathrm{M}$ :

$$
\begin{aligned}
\frac{\text { Rate }_{\mathrm{OD}}}{\text { Rate }_{\mathrm{B}-\mathrm{VL}}} & =\frac{4.29 \times 10^{-6} \mathrm{M} \cdot \mathrm{min}^{-1}}{0.0138 \mathrm{M} \cdot \mathrm{min}^{-1}} \\
& =3.11 \times 10^{-4} \mathrm{M} \\
\mathrm{ODD} & / \mathrm{M}_{\beta-\mathrm{VL}}
\end{aligned}
$$

Therefore, in THF solution, carbonylation of EB in the presence of $4-\mathrm{F}-\mathrm{C}_{6} \mathrm{H}_{4} \mathrm{NCO}(0.67 \mathrm{M})$ should yield $\sim 0.03 \%$ ODD. This is expected to be even smaller for lower concentrations of $4-$ $\mathrm{F}-\mathrm{C}_{6} \mathrm{H}_{4} \mathrm{NCO}$. 